\title{
Challenge Test Improvement: Analytical Costs and Time
}

\section{Optimization}

\author{
Marco Romani $^{1^{*}} \&$ Chiara Romani ${ }^{1}$ \\ ${ }^{1}$ Merieux Nutrisciences, Prato, Italy \\ *Marco Romani, E-mail: marco.romani@ mxns.com
}

Received: October 1, 2017

Accepted: October 10, 2017

Online Published: October 18, 2017

doi:10.22158/fsns.v1n2p100

URL: http://dx.doi.org/10.22158/fsns.v1n2p100

\begin{abstract}
The study's aim was to develop a quantitative risk assessment model of Listeria monocytogenes in liver chicken paté. The model was performed using the Integrated Challenge Test (Italian Journal of Food Safety, Vol. 1 N. 6 2012) with the objective to reduce the analytical cost and time. The challenge test was carried out on 3 different batches stored at $12^{\circ} \mathrm{C}$ and inoculated with a mix of Listeria monocytogenes strains. Lactobacillus spp. and Listeria monocytogenes plate counts were performed daily on each sample until the stationary phase was reached by both populations. The challenge test results at $12^{\circ} \mathrm{C}$ were input in the Combase DMfit software to determine the growth parameters of Listeria monocytogenes and lactic flora which showed mutual interaction. Then, using the Combase Predictor for Listeria monocytogenes and the FSSP (Food Spoilage and Safety Predictor) software for lactic flora, the growth parameters were extrapolated at $4^{\circ} \mathrm{C}$ and $8^{\circ} \mathrm{C}$. The growth parameters of both populations at $4{ }^{\circ} \mathrm{C}, 8^{\circ} \mathrm{C}$ and $12^{\circ} \mathrm{C}$ were then used to apply the model in order to predict the maximum daily concentration of Listeria monocytogenes. Model results were assessed against the results of an additional challenge test conducted with the same strain mix inoculum in 3 different batches stored for 4 days at $4{ }^{\circ} \mathrm{C}, 4$ days at $8^{\circ} \mathrm{C}$ and then 4 days at $12^{\circ} \mathrm{C}$. The proposed model represents a reliable quantitative risk evaluation which provides realistic results with limited cost.
\end{abstract}

\section{Keywords}

Listeria monocytogenes, challenge test, anti-listerial activity, lactic acid bacteria, predictive microbiology

\section{Introduction}

The Integrated Challenge Test was created in response to ANSES guide (November 2008) to focus on its strengths and overcome its limitations. The first version of the Integrated Challenge Test (Italian Journal of Food Safety, Vol. 1, No. 6, December 2012) aimed to develop a quantitative risk assessment model of L. monocytogenes starting with experimental data only. This involved high analytical cost and 
time. Therefore, the following steps consisted in providing a more accessible model without compromising the scientific strictness. The current version of the Integrated Challenge Test starts with experimental results, but uses predictive microbiology to extrapolate that data which, if obtained experimentally, would have greatly increased the cost and time.

The model has been developed on a sample of liver chicken paté (RTE food) that, for the values of the chemical-physical parameters ( $\mathrm{pH}$ and $\mathrm{Aw}$ ) and the growth potential (>0.5 $\log \mathrm{cfu} / \mathrm{g}$ ), can support $\mathrm{L}$. monocytogenes growth. This model is applicable also to the cooked meat products in which the lactic flora is predominant (example: sliced cooked ham, sliced mortadella, fresh sauces).

\section{Method}

The microbiological population of the product was mainly composed of lactic flora that was subjected to the following tests: agar well diffusion assay (Parente et al., 1994) and agar drop test (Paparella et al., 1992). The first test aimed to evaluate the antilisterial activity; the second one determined the substances with antilisterial activity. Later a challenge test was conducted on three batches (three repetitions for batch). Selected L. monocytogenes strains, most meat isolates, were grown at $8^{\circ} \mathrm{C}$ to post exponential phase, mixed and inoculated in liver paté samples (approximately $1.6 \mathrm{log} \mathrm{cfu} / \mathrm{g}$, according to the ANSES guide, November 2008). The samples were incubated at $12^{\circ} \mathrm{C}$ and tested daily for L. monocytogenes plate count (UNI EN ISO 11290-02: 2005) and Lactic acid bacteria plate count (UNI EN ISO 15214: 1998).

Microbiological analysis were conducted until the stationary phase of both populations (1 week). The challenge test was conducted at $12^{\circ} \mathrm{C}$ because the time to reach by both population the stationary phase occurred in a short time (1 week). This allowed to speed the study, reducing costs significantly (at $4^{\circ} \mathrm{C}$ the lactic flora reaches the stationary phase after 20 days). L. monocytogenes and lactic flora growth data were then put in Combase DMfit software in order to determine the growth curves and parameters: lag phase (days), daily growth rate (log/day), beginning of the stationary phase (days) and concentration of the stationary phase (log cfu/g). Starting from the average growth parameters at $12^{\circ} \mathrm{C}$, growth parameters (lag phase and growth rate) were extrapolated at $4{ }^{\circ} \mathrm{C}$ and $8^{\circ} \mathrm{C}$ using two predictive software (ComBase Predictor and FSSP) and the formula of Baranyi Roberts relating to the physiological state of the microorganisms [physiological state $=1 / 10^{\text {(lag phase } \mathrm{x} \text { growth rate) }}$. The experimental data at $12^{\circ} \mathrm{C}$ with those extrapolated at $4{ }^{\circ} \mathrm{C}$ and $8^{\circ} \mathrm{C}$ were used to set the model which, taking also in consideration the difference time between L. monoctogenes and lactic flora stationary phase, aimed to define the maximum concentration reached by the pathogen in the liver chicken pate stored 4 days at $4{ }^{\circ} \mathrm{C}, 4$ days at $8^{\circ} \mathrm{C}$ and 4 days at $12^{\circ} \mathrm{C}$.

The model was then statistical assessed (t-test) against real data coming from a challenge test carried out according to the same time-temperature profile: 4 days at $4^{\circ} \mathrm{C}, 4$ days at $8^{\circ} \mathrm{C}$ and 4 days at $12^{\circ} \mathrm{C}$. The t-test was applied to the averages of the experimental and predictive data (95\% confidence limit). 


\section{Result}

Agar well diffusion assay showed that the indigenous lactic flora had antilisterial activity against $L$. monocytogenes strains used for inoculation. Agar drop test showed that such activity is supported by organic acids. In table 1 the averages of growth parameters of lactic flora and L. monocytogenes at $4^{\circ} \mathrm{C}$, $8^{\circ} \mathrm{C}$ and $12^{\circ} \mathrm{C}$ are reported. From Table 1 it can be observed that at $12^{\circ} \mathrm{C}$ L. monocytogenes achieved the stationary phase 0.43 days before lactic flora. This result with the other growth parameters permitted the development of the model.

Table 1. Average Values of the Growth Parameters of L. monocytogenes (L.m.) and of Lactic Acid Bacteria (LAB) at the Temperatures of $4^{\circ} \mathrm{C}, 8^{\circ} \mathrm{C}, 12^{\circ} \mathrm{C}$. The Table Shows the Values Used for the Development of the Model

\begin{tabular}{lllllllll}
\hline LAB & LAB & LAB & LAB & L.m. & L.m. & L.m. & L.m. \\
& Lag & Growth & Stationary & Stationary & Lag & Growth & Stationary & Stationary \\
& phase & Rate & phase & phase & phase & Rate & phase & phase \\
& days & log/day & $\log$ cfu/g & days & days & $\log /$ day & $\log$ cfu/g & days \\
\hline $4^{\circ} \mathrm{C}$ & 4,78 & 0,37 & $/$ & $/$ & 5,62 & 0,15 & $/$ & $/$ \\
$8^{\circ} \mathrm{C}$ & 1,95 & 0,92 & $/$ & $/$ & 2,52 & 0,33 & $/$ & $/$ \\
$12^{\circ} \mathrm{C}$ & 1,05 & 1,70 & 8,96 & 5,22 & 1,26 & 0,66 & $/$ & 4,79 \\
\hline
\end{tabular}

The statistical comparison (T-test) between L. monocytogenes maximum concentration coming from the experimental challenge test and the predictive model (Table 2) showed a slight difference. The model underestimated the reality by little $(<0.5 \log )$, suggesting the possibility to correct the average predictive data $(3.43 \mathrm{log} \mathrm{ufc} / \mathrm{g})$ with the limit of $95 \%$ confidence. Since the model underestimated the reality, the correction of the predictive data consisted in adding the upper limit of the confidence interval $(-0.47 \log )$.

Table 2. Comparison of the Average of Predictive and Experimental Data Regarding the Maximum Concentration of $L$. monocytogenes among the Three Batches. The Lower Confidence Limit (LCL) and the Upper Confidence Limit (UCL) were also Calculated: Confidence Interval $95 \%$

\begin{tabular}{lll}
\hline Challenge test & $\begin{array}{l}\text { Predictive data } \\
\text { Log cfu/g }\end{array}$ & $\begin{array}{l}\text { Experimental data } \\
\text { Log cfu/g }\end{array}$ \\
\hline $1^{\circ}$ batch, $1^{\circ}$ rep. & 3,42 & 3,74 \\
$1^{\circ}$ batch, $2^{\circ}$ rep. & 3,33 & 3,72 \\
$1^{\circ}$ batch, $3^{\circ}$ rep. & 3,47 & 4,15 \\
$2^{\circ}$ batch, $1^{\circ}$ rep. & 3,61 & 3,90 \\
$2^{\circ}$ batch, $2^{\circ}$ rep. & 3,54 & 3,80 \\
\hline
\end{tabular}




\begin{tabular}{lll}
\hline $2^{\circ}$ batch, $3^{\circ}$ rep. & 3,46 & 3,95 \\
$3^{\circ}$ batch, $1^{\circ}$ rep. & 3,42 & 3,52 \\
$3^{\circ}$ batch, $2^{\circ}$ rep. & 3,39 & 3,70 \\
$3^{\circ}$ batch, $3^{\circ}$ rep. & 3,21 & 3,78 \\
Average & $3,43^{\mathrm{a}}$ & $3,74^{\mathrm{b}}$ \\
Lower Confidence Limit (LCL) & $\mathbf{- 0 , 2 3 ~ l o g}$ & \\
Upper Confidence Limit (UCL) & $\mathbf{- 0 , 4 7 ~ l o g}$ & \\
\hline
\end{tabular}

\section{Discussion}

The study shows that the proposed quantitative risk assessment model is very realistic because taking into consideration the characteristics of the food, as well as the growth parameters of lactic flora and of $L$. monocytogenes, it is possible to predict the maximum concentration of the pathogen very closely the real data. Also, the use of predictive microbiology for the extrapolation of data at temperatures at which the experimental test would be extended too much, gives the integrated challenge test a greater commercial value. Food companies can implement the integrated challenge test at an affordable cost which is immediately translated into a competitive advantage. The proposed model, in fact, is reliable and provides an accurate quantitative risk assessment with limited cost as the result of synergy between experimental and predictive data. Knowing the concentration of lactic flora and L. monocytogenes at any time of the shelf life, the model allows a determination of the maximum L. monocytogenes concentration.

\section{References}

Beaufort, Bergis, Lardeux, \& Lombard. (2008, November). Technical guidance document on shelf life studies for Listeria monocytogenes in ready to eat foods.

Colombo, S., Romani, M., Romani, C., \& Matteini, P. (2012). Il Challenge test Integrato. Italian Journal of Food Safety, 1(6).

Paparella, A., Ruocco, G., \& Barbieri, B. (1992). Lattobacilli come inibitori della microflora delle carni fresche.

Parente, E., Brienza, C., Moles, M., \& Ricciardi, A. (1995). A comparison of methods for the measurement of bacteriocin activity. J. Microbiol. Meth., 22, 95-108. https://doi.org/10.1016/0167-7012(94)00068-I

UNI EN ISO 11290-2/A1. 2005.

UNI EN ISO 15214:1998. 1998. 